\title{
The staining of lactic dehydrogenase isoenzymes after electrophoretic separation on cellulose acetate
}

\author{
H. BARNETT \\ From the Pathology Department, South London Hospital for Women
}

SYNOPSIS Established electrophoretic techniques for the separation of the lactate dehydrogenase (L.D.H.) isoenzymes of tissues and body fluids, although of value in clinical medicine, are too elaborate for most routine laboratories. A simple method for the separation of these isoenzymes on cellulose acetate and their histochemical staining is described.

Spectrophotometric estimations of the total L.D.H. activity performed on eluates of electrophoretically separated samples showed that there was no significant loss of enzyme activity during electrophoresis.

The effects of alterations in $p \mathrm{H}$ and other practical features are discussed briefly.

It is concluded that by this method isoenzymes can be studied with the same apparatus and the same routine facility as are serum proteins.

Various electrophoretic techniques have been used to separate the lactate dehydrogenase (L.D.H.) of tissues and body fluids into several enzymatically active components or 'isoenzymes' (Ann. N.Y. Acad. $S c i ., 1961)$. The isoenzyme pattern is derived from the relative activities of these components and is characteristic for the tissue from which the enzyme is obtained (Wieland and Pfleiderer, 1957; Sayre and Hill, 1957; Wieme, 1959; Plagemann, Gregory, and Wróblewski, 1960; Vesell and Bearn, 1961). In disease the normal serum pattern is altered to reflect that of the organ damaged by necrosis (Wieme, 1959; Wróblewski, Ross, and Gregory, 1960; Hill, 1961; Vesell and Bearn, 1961; Vesell, 1961; Latner and Skillen, 1961; Van der Helm, 1962), so that these findings have been of value to clinical pathologists in the diagnosis of liver and heart necrosis. However, as has been stressed by many workers in this subject (Latner and Skillen, 1961; Van der Helm, 1962), the wider use of this diagnostic technique is dependent on the development of simple procedures which are suitable for routine hospital laboratories. The earlier electrophoretic separations on starch and agar gels, with the need of elution from the former, and the necessity of scanning with ultraviolet light with the latter, were too elaborate for most routine laboratories. Some improvement in this situation occurred when it was found possible to replace these pro-

Received for publication 5 December 1963. cedures with a histochemical staining reaction (Markert and Møller, 1959; Latner and Skillen, 1961; Van der Helm, 1962; Wieme, Van Sande, Karcher, Loewenthal, and Van der Helm, 1962), and a further significant advance towards widespread study of isoenzymes was the improved electrophoresis tank and method of Wieme (Wieme et al., 1962). Despite these improvements, the complete technique is still too complex and costly in apparatus, even in the many laboratories which routinely investigate the electrophoretic separation of plasma proteins on cellulose acetate (Kohn, 1957, 1959). Although such electrophoretic procedures have received general acceptance because of their simplicity and reproducibility, they have not been applied generally to the study of isoenzymes. This is due to the fact that isoenzymes are not retained on the strip during the histochemical procedure, so that some elution technique had to be used. The purpose of this communication is to describe a histochemical staining method for dehydrogenase activity, which can be applied to electrophoretic separations on cellulose acetate, and which should therefore make the study of isoenzymes in serum as simple and routine a procedure as is the separation of serum proteins.

\section{MATERIALS}

MEDIUM FOR ELECTROPHORESIS A $0.07 \mathrm{M}$ solution of barbiturate buffer (diethyl barbituric acid and sodium diethyl barbiturate) at $p \mathrm{H} \mathrm{8.6.}$ 
INCUBATION MEDIUM An approximate $0 \cdot 1 \mathrm{M}$ solution of sodium lactate at $p H \mathbf{H} 7$ is prepared by mixing $1 \mathrm{ml}$. $1 \mathrm{M}$ lactic acid with approximately $11 \mathrm{ml}$. of a $1 \mathrm{M}$ solution of sodium hydroxide; this solution is heated to $90^{\circ} \mathrm{C}$. for five minutes, cooled, reheated, and cooled again; the $p \mathrm{H}$ is then adjusted to 7.4 by the addition of more sodium hydroxide.

The complete incubation medium is prepared as follows:

The approximate $0 \cdot 1 \mathrm{M}$ solution of sodium lactate. ...... vol. $1 \%$ solution, in distilled water, of N.A.D. . . . . . . . . $0.1 \%$ solution, in distilled water, of M.T.T. 3(4,5-dimethylthiazolyl-2) $-2,5$-diphenyltetrazolium bromide.............. 3 vol. $0.1 \%$ solution, in distilled water, of phenazine methosulphate (prepared freshly before use) $\ldots \ldots \ldots \ldots \ldots \ldots \ldots \ldots \ldots \ldots .3 .6 \ldots \ldots$.

THE FIXATIVE This is made up as follows:-

Formal saline ( $4 \%$ formaldehyde in $0.85 \%$ saline) . . . . $\ldots 1$ vol.

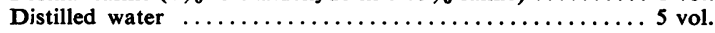

CELlulose ACETATE STRIPS These are prepared in duplicate. For electrophoresis with a bridge $8 \mathrm{~cm}$. long, strip A (see below) should be $9 \mathrm{~cm}$. long by $2.5 \mathrm{~cm}$. wide. Strip B, used for holding the incubation medium, should be $7 \mathrm{~cm}$. long by $2.5 \mathrm{~cm}$. wide; in this way expensive reagents are not wasted.

SAMPLES Both homogenates and undiluted serum were used. The former were prepared from tissues which were first minced and then washed with normal saline repeatedly to remove blood. The wet tissue was ground in a Potter-Elvhjem type of homogeniser; the homogenate was suspended in a $7 \%$ solution of bovine serum albumin in $\mathrm{M} / 15$ Sørensen phosphate buffer $p H \mathbf{H} 7 \cdot 4$, and centrifuged at $3,000 \mathrm{~g}$ for five minutes. The supernatant was diluted as required for electrophoresis.

\section{METHOD}

The procedure for the electrophoretic separation of isoenzymes is identical with that of $\operatorname{Kohn}(1957,1959)$ for the separation of plasma proteins, except that the sample, about 2-5 $\mu 1$., is applied at the centre of strip A and the run lasts one and a quarter hours. A drop of bovine serum albumin, coloured with bromophenyl blue, is applied close above this sample, and serves as a marker from which absolute mobilities may be calculated. Since the incubation medium must be freshly prepared, it is advisable to prepare it towards the end of the run. For a strip B of the size indicated above, $0.25 \mathrm{ml}$. of incubation medium is added to the bottom of a Petri dish $(9 \mathrm{~cm}$. diameter) and strip $B$ is floated on the

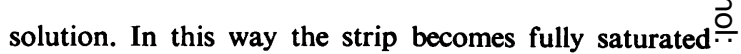
but not overloaded. These directions are relatively $\overrightarrow{\vec{F}}$ critical; excess of incubation medium will cause diffusion of isoenzyme bands, whereas insufficiency will cause premature drying during incubation.

Strip $A$ is removed from the tank. In order to make it $\frac{\bar{\omega}}{2}$ identical in size with strip $B, 1 \mathrm{~cm}$. is trimmed off each edge and it is then superimposed on strip B; care should be taken to avoid bubbles. These procedures must be ${ }^{\infty}$ effected rapidly to avoid drying. The Petri dish is then $\overrightarrow{0}$ closed and incubated at $37^{\circ} \mathrm{C}$. for up to 30 minutes, $\rightarrow$ after which the strips are fixed in formol saline for five to $\vec{\omega}$ 15 minutes, when they separate. They are blotted and 2 dried between filter paper under pressure to avoid응 curling.

SPECTROPHOTOMETRIC ESTIMATION OF TOTAL L.D.H.نं ACTIVITY Tests were performed on sera and tissue homogenates to see whether enzyme activity was losto during electrophoresis. The samples were eluted by cutting out the whole electrophoretic area from the $\vec{c}$ cellulose acetate and immersing it in phosphate buffer $\mathbb{D}$ pH 7.4. Enzyme activity was determined in these samples $\frac{\vec{D}}{\mathbb{D}}$ by the method of Wróblewski and La Due (1955).

\section{RESULTS}

ENZYME RECOVERY To examine whether any enzyme activity was lost during electrophoresis, tests were performed on sera from cases of myo-cardial infarction and liver disease; from fluido aspirated from skin blisters from patients with

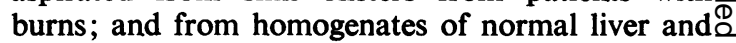
heart removed at necropsy. Table I summarizes $\overrightarrow{\vec{O}}$ these results.

pH OF INCUBATION MEDIUM AND ITS EFFECT ON THE REACTION The incubation medium, in which strip $B-$ is saturated, is prepared in distilled water. The $p H^{\circ}$ of this solution was found to be $5 \cdot 8$. For incubation, 3 strip B was added to strip A which itself wasi saturated with $0.07 \mathrm{M}$ solution of barbiturate buffer윽 at $p \mathrm{H} \mathrm{8.6.} \mathrm{The} \mathrm{histochemical} \mathrm{reaction} \mathrm{occurred} \mathrm{in}$ both strips, showing free diffusion from one to the other. Hence it was assumed that the final $p \mathrm{H}$ at which the reaction occurred was that of a solution containing equal volumes of the incubation medium $\mathrm{N}$ and of the barbiturate buffer.

TABLE I

RECOVERY OF TOTAL L.D.H. ACTIVITY

$\begin{array}{lll}\begin{array}{l}\text { Serum from Case Serum from Case Blister Fluid } \\ \text { of Liver Disease of Myocardial }\end{array} & \begin{array}{l}\text { Liver } \\ \text { Homogenate }\end{array} & \begin{array}{l}\text { Heart } \\ \text { Homogenate }\end{array}\end{array}$

Activity in sample (Wróblewski units, in duplicate samples)

Activity in eluate (Wróblewski units, in duplicate samples)

$500, \quad 700$

700,600
$1,200, \quad 1,350$

$1,100,950$
$1,300, \quad 1,500$

$1,600,1,640$
$1,500,1,600$

850, 900

$1,400,1,500$

700 
One volume of the incubation medium was added to one volume of the barbiturate buffer. The $p \mathrm{H}$ of this mixture was 7.6. For comparison, an incubation medium was prepared in which the N.A.D., the M.T.T., and the phenazine methosulphate were dissolved in $0.07 \mathrm{M}$ barbiturate buffer at $p \mathrm{H} \mathrm{8.6.} \mathrm{The}$ final $p \mathrm{H}$ of this mixture was depressed to $7 \cdot 4$ apparently due to the acidifying effect of the M.T.T. ( $p \mathrm{H} \mathrm{7 \cdot 2)}$ and the phenazine methosulphate $(p H 7 \cdot 8)$ when dissolved in this buffer. When one volume of this mixture was added to one volume of the electrophoresis buffer, the final $p \mathrm{H}$ was 8.6. When the strip B was saturated with this buffered incubation medium and incubated with strip A which had been used for a normal electrophoretic separation, it was found that the intensity of the isoenzyme bands was apparently identical to those incubated in the normal incubation medium; the background colour, however, was heightened, making such strips less suitable for scanning.

STAINING OF THE SEPARATED ISOENZYMES When the strips were stained by the histochemical procedure, the sites of activity were disclosed as sharply defined purple bands. The pattern on both strips was identical; with longer incubation time the lower strip B became progressively stronger than strip A. It is advisable to select the stronger strip for inspection or scanning. The rate of movement of the isoenzymes from one strip to the other appeared to be identical in that the relative densities of the bands remained constant.

Up to five bands were found in homogenates of human liver, heart, kidney, skin, leucocytes, in lysates of red cells, and in various human sera. The results agreed well with those reported with other techniques (Fig. 1). In normal serum the anodic fractions L.D.H.1, L.D.H.2, and L.D.H.3 only were strongly active, so that larger aliquots of serum were required if L.D.H.4 and L.D.H.5 were to be detected. The enhancement of activity of L.D.H.1 and L.D.H. 2 that occurs in the serum of cases of myocardial infarction, and the very marked increase in L.D.H.5 that is diagnostic of liver disease can be observed by superficial inspection (Fig. 2).

For accurate quantitative determination of isoenzyme pattern the strips were cleared in Whitmore oil 120 (Kohn, 1959) and were scanned in an automatic scanner (Chromoscan, Joyce, Loebl, and Company). Only those strips were selected in which bands were uniform in colour and where no background gradients of colour occurred (Fig. 3).

\section{DISCUSSION}

Cellulose acetate is widely used as a supporting medium for electrophoretic separation of plasma

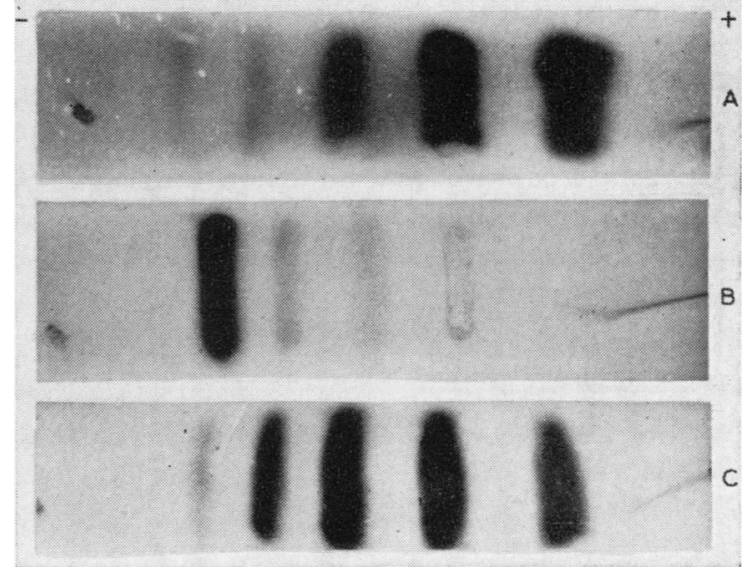

FIG. 1. L.D.H. isoenzyme pattern of human tissue homogenates in $A$, heart; $B$, liver; $C$, Kidney.

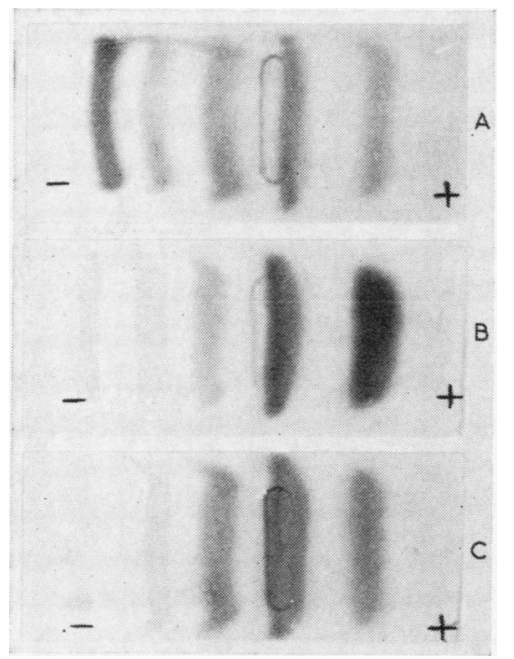

FIG. 2. L.D.H. isoenzyme pattern in human serum in $A$, serum in acute hepatitis; $B$, serum in myocardial infarction; $C$, normal serum.

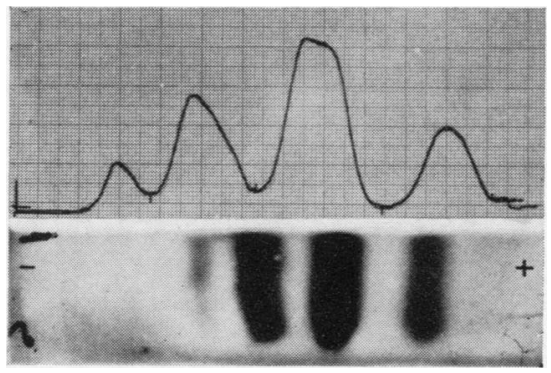

FIG. 3. L.D.H. isoenzyme pattern in serum with scan. 
proteins, particularly in routine laboratories. The obvious extension of such studies is to the separation of isoenzymes in serum, preferably with the use of the histochemical method to demonstrate the bands. Yet this was impossible, since the porosity of cellulose acetate was so great that all the enzyme was lost into the incubation medium when the electrophoretic strip was immersed in it. In the method described in this communication, the incubation medium is applied to the electrophoretic strip by the apposition of a second strip saturated with the incubation medium. The sensitivity of this method can be assessed from the fact that three bands have been demonstrated in $5 \mu \mathrm{l}$. of a serum which contained only 100 Wróblewski units. Moreover, it has been demonstrated that enzyme recovery from the strip, when tested by elution, is complete (Table I). Thus it follows that it is now possible to estimate the contents of L.D.H. isoenzymes in human serum with the same apparatus, and the same ease, as is effected for the analysis of plasma proteins of human serum.

Certain practical features merit further consideration. It is likely that overloading of the strip with enzyme can occur, with consequent disturbance of apparent isoenzyme pattern. Ideally, the total concentration of lactic dehydrogenase should not exceed 1,200 Wróblewski units; in practice this means that the sample should be diluted until the bands require two or three minutes before they begin to stain with the histochemical reaction. The $p \mathrm{H}$ of the reaction is maintained rather low, to reduce background colour. However, the intensity of the reaction in the bands is apparently identical whether the reaction is performed at $p \mathrm{H} 8.6$ or $p \mathrm{H}$ $7 \cdot 6$, as in the present method. It appears, therefore, that the critical factor in determining the equilibrium of the lactate-pyruvate system is the rate of removal of the hydrogen, which is effected by the phenazine methosulphate. This hydrogen acceptor is very unstable, particularly at higher $p \mathrm{H}$ values, hence the advantage of having the reaction at a high $\mathrm{pH}$ to assist the reaction to progress from lactate to pyruvate may be contradicted by the decomposition of the hydrogen acceptor at such $p \mathrm{H}$ values. It is possible that the cyanide, which is usually added to the incubation medium to remove pyruvate from the equilibration system, is unnecessary under the present conditions because the removal of the $\overrightarrow{\vec{s}}$ hydrogen by the phenazine methosulphate, which 0 may be the more critical factor, is sufficiently rapid.

The method described in this communication can $\bar{\omega}$ be applied, with suitably modified incubation media, $\overparen{\curvearrowright}$ for the detection of other dehydrogenase isoenzymes. However, it should be noted that particularly where ${ }^{\text {s }}$ high concentrations of serum or homogenates have $\overrightarrow{0}$ to be used for the study of other enzymes in low $\vec{A}$ concentration, weak reactions may be observed at $\stackrel{\omega}{\omega}$ the site of the L.D.H. isoenzymes in the absence of lactate. This activity, which appears to represent? true lactic dehydrogenase activity acting on enzymebound substrate, will be considered more fully or elsewhere. The albumin of serum and body fluids also shows apparent dehydrogenase activity with $\mathrm{O}$ this histochemical test; this would appear to be due $?$ to non-enzymatic reduction of the M.T.T. and will $c$ also be the subject of a further communication.

I wish to acknowledge my gratitude to Dr. J. Kohn for his stimulating interest and encouragement in this work $\underset{\square}{\mathbb{D}}$ and for the laboratory facilities which he afforded me. $\vec{\oplus}$ I also wish to thank Mr. T. O. Kelly for his help over $\mathscr{O}$ biochemical problems. I am indebted to Dr. L. Bitenski . and Dr. J. Chayen for helpful discussions. The financial help of the British Empire Cancer Campaign is gratefully acknowledged.

\section{REFERENCES}

Ann. N.Y. Acad. Sci. (1961). 94, 665-1030.

Hill, B. R. (1961). Cancer Res., 21, 271.

Kohn, J. (1957). Clin. chim. Acta, 2, 297.

- (1959). Ibid., 3, 450.

Latner, A. L., and Skillen, A. W. (1961). Lancet, 2, 1286.

Markert, C. L., and Møller, F. (1959). Proc. nat. Acad. Sci. (Wash.), 45, 753.

Plagemann, P. G. W., Gregory, K. F., and Wróblewski, F. (1960). $\frac{\Omega}{0}$ J. biol. Chem., 235, 2282, 2288.

Sayre, F. W., and Hill, B. R. (1957). Proc. Soc. exp. Biol. (N. Y.), 96, 695.

Van der Helm (1962). Clin. chim. Acta, 7, 124

Vesell, E. S. (1961). N.Y. Acad. Sci., 94, 877.

- and Bearn, A. G. (1961). J. clin. Invest., 40, 586.

Wieland, Th., and Pfleiderer, G. (1957). Biochem. Z., 329, 112.

Wieme, R. J. (1959). Studies on Agar Gel Electrophoresis: Techniques,

Applications. Arscia Uitgaven. Brussels.
Van Sande, M., Karcher, D., Loewenthal, A., and Van der Helm, 을 H. J. (1962). Clin. chim. Acta, 7, 750.

Wróblewski, F., and La Due, J. S. (1955). Proc. Soc. exp. Biol. (N.Y.), N $90,210$.

_-, Ross, C., and Gregory, K. (1960). New Engl. J. Med., 263, 531. N 